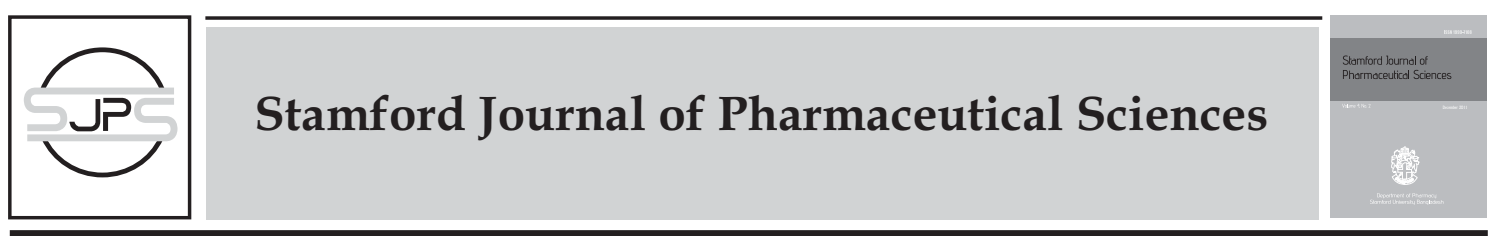

\title{
Toxicological studies of Darvyadi Kvatha Curna using albino rats
}

\author{
*Dilshad Yasmin', M.S.K. Choudhuri², Riaz Uddin' \\ ${ }^{1}$ Department of Pharmacy, Stamford University Bangladesh, 51, Siddeswari Road, Dhaka-1217, Bangladesh \\ ${ }^{2}$ Department of Pharmacy, Jahangirnagar University, Savar, Dhaka-1342, Bangladesh
}

Original Research Article

\begin{abstract}
Darvyadi Kvatha Curna (DVY), is an Ayurvedic preparation which is used in leucorrhoea in the rural population as a traditional medicine. This Ayurvedic preparation was administered chronically to the male and female rats to explore the toxicological characteristics of this preparation. After the administration of DVY preparation for a period of 45 days, the following biochemical parameters (protein, albumin.triglyceride, cholesterol, LDL, VLDL, HDL, creatinine, uric acid, urea, and bilirubin) in the plasma of both the male and female rats were determined. In the study the total protein content in the plasma was increased $(2.75 \%)$ in the DVY treated male rats. The result showed no significant difference between the control and the DVY treated groups; but the $p$ value, though was not significant yet it was noticeable $(p=0.073)$. Interestingly, the albumin content was significantly increased (17.21\%) in DVY treated male rats. In the female rats group the total protein and the albumin content in the plasma were also increased in comparison to their control groups. A statistically significant (13.46\%) increase was noted only in the case of albumin. In the male rats there was a significant decrease in the Triglycerides content in the plasma. After chronic administration of the traditional medicine the triglyceride level was $31.15 \%$ decreased in male rats group. Also insignificant decrease was noted in the total Cholesterol and HDL content in the plasma with $4.12 \%$ and $1.07 \%$ decrease respectively. Besides insignificant increase was noted in the VLDL content in the plasma with $18.16 \%$ increase. But only in the case of the content of the LDL in plasma a significant decrease $(12.72 \%$ decr.) was noted. In the female rats there was a significant decrease in the Triglycerides content in the plasma. Here the test medicine also decreased the triglyceride level by $9.47 \%$ in female rats group. Also an insignificant decrease in the total Cholesterol, VLDL, LDL and HDL content in the plasma was noted with $4.12 \%, 6.94 \%, 2.46 \%$ and $0.78 \%$ decrease respectively. In the male rats there was a significant decrease $(51.37 \%)$ in the Bilirubin content in the plasma. In the female rats there was a significant increase (33.38\%) in the Bilirubin content in the plasma. There was an increase in the plasma creatinine $(2.28 \%)$ in the DVY treated male rats, though this increase was not significant, yet noticeable $(\mathrm{p}=0.072)$. On the contrary, a significant decrease in the urea $(11.90 \%)$ content in plasma was noted. In female rats, there was a significant decrease in both the Creatinine (36.60\%) and Urea $(7.72 \%)$ content in the plasma. It was observed that about $11.71 \%$ decrease in plasma uric acid content of DVY treated male rats in comparison to their control male rats which is statistically significant. It was observed that the female rats showed significant increase in the concentration of uric acid (11.68\%) level in comparison to their control female rats.
\end{abstract}

Keywords: Ayurvedic, biochemical parameters, albumin, protein, creatinine, bilirubin

\section{INTRODUCTION}

Shweta pradara is a very common disease in female. Leucorrhoea, commonly known as whites, refers to a whitish discharge from the female genitals. Leucorrhoea is an abnormal condition of the reproductive organs of

*Corresponding Author:

Dilshad Yasmin, Lecturer

Department of Pharmacy, Stamford University Bangladesh, 51, Siddeswari Road, Dhaka-1217

Contact no. : 01751-068531 women. It is an abnormal excessive vaginal discharge often associated with irritation and pruritus (Bose and Bose, 1996). If not treated properly in the initial stages, it may become chronic. It is considered to be as one of the major problems among the reproductive age group women (Kulkarni and Durge, 2005). It is generally caused due to unhygienic conditions and microbial infection in female genital tract (Morphemeremedies, Online document). Weak body immunity is also an important factor in case of leucorrhoea. 
Darvyadi Kvatha Curna (DVY) is included in the Bangladesh National Formulary of Ayurvedic Medicine 1992 (Approved by the Government of Bangladesh vide Ministry of Health and Family Welfare Memo No. Health1/Unani-2/89/ (Part-1) 116 dated 3-6-1991) (Anonymous, 1992). Costly and extensive procedures of clinical investigations can be

\section{MATERIALS AND METHODS}

Darvyadi Kvatha Curna (DVY) was collected from Sri Kundeswari Aushadhalaya Ltd., Chittagong for the toxicological study. All other reagents and chemicals that were used in this work were of analytical grade and were prepared in all glass-distilled water

Table 1: Plants used in the formulation of Darvyadi Kvatha Curna.

\begin{tabular}{llll}
\hline Name of Plants & Used parts & Botanical name & Family \\
\hline $\begin{array}{l}\text { Darvi (Daruharidra) } \\
\text { Rasanjana } \\
\text { (Daruharidra) }\end{array}$ & $\begin{array}{l}\text { Stem } \\
\text { Solid Extract of Darvi }\end{array}$ & $\begin{array}{l}\text { Berberisaristata } \\
\text { Berberisaristata }\end{array}$ & Berberidaceae \\
Vrsa (Vasa) & Root & Adhatoda vasica & Acanthaceae \\
Abda(Musta) & Rhizome & Cyperusrotundus & Cyperaceae \\
Kirata (Kiratatikta) & Plant and leaves & Swertia chirata & Gentianaceae \\
Bilva & Fruit powder & Aegle marmelos & Rutaceae \\
Bhallataka (Suddha) & Fruit & Semecarpus anacardium & Anacardiaceae \\
Kairava (Kumuda) & Flower & Nymphaea rubra & \\
\hline
\end{tabular}

avoided in many cases by using Ayurvedic medicine and people in this selected region have the preference to get treatment at a cheaper price depending on their choice (Khan, 1994; WHO, 2002).

Taking into consideration, the widespread use of Ayurveda as the popular form of TM in Bangladesh (Ghani, 2005), one cannot emphasize enough the need for establishing the safety profiles of Ayurvedic drugs. Keeping in mind, the present research work on Ayurvedic formulation, Darvyadi Kvatha Curna (DVY) explores a spectrum of its toxicological aspects utilizing experimental animals. The aim is to have a better understanding of the possible toxicological profile of the drug under study and to some extent, to decide how reasonable the use of this drug is under the stated circumstances. Darvyadi Kvatha Curna is formulated from different parts of eight medicinal plants (Table 1). Dose regimen is $48 \mathrm{~g}$ in divided doses. It should not be given to the patients who are allergic to bhallataka (pitta-prakrti) and in place of the drug; raktacandana should be used for this preparation. It should not be used in summer season. Before taking this medicine the mucous membrane of the mouth should be smeared with ghee.

\section{Preparation of the Extract}

The kwath was prepared from dried powder according to the procedure mentioned in Bangladesh National Ayurvedic Formulary (BNAF) (Anonymous, 1992). The kwath was prepared by adding $160 \mathrm{ml}$ of distilled water with $5 \mathrm{~g}$ of the powder and it was thoroughly mixed to make a uniform suspension, it was then boiled till the volume was reduced to 40 $\mathrm{ml}$ and was finally filtered. This filtrate was collection I. Then residue was again boiled with $160 \mathrm{ml}$ of water till the volume was reduced to $40 \mathrm{ml}$ and was then filtered. This filtrate was collection II. The two filtrates (collection I and II) were mixed and reduced to $20 \mathrm{ml}$ and this mixture was known as kwath and was used for the toxicological study.

\section{Dose and Route of administration}

For the toxicological experiment, the kwath was administered at a volume such that it would permit optimal dosage accuracy. For the toxicological studies the drug was administered per oral route at a dose of 40 $\mathrm{ml} / \mathrm{kg}$ of the body weight. For the toxicological studies, the kwath was administered orally. Ketamine were administered intra-peritoneally (500 mg/kg i.p.). 


\section{Experimental Animal}

Eight-week old albino rats (Rattus novergicus: Sprague-Dawley strain) of both sexes, bred and maintained at the Animal House of the Department of Pharmacy, Jahangirnagar University were used in the toxicological experiment. These animals were apparently healthy and weighed 50-70 g. Under constant environmental and adequate nutritional conditions the animals were housed in a well ventilated hygienic experimental animal house throughout the period of the experiment. All of the rats were kept in plastic cages having dimensions of $30 \times 20 \times 13 \mathrm{~cm}$ and soft wood shavings were employed as bedding in the cages. Feeding of animals was done ad libitum, along with drinking water and maintained at natural day night cycle. They were fed with "mouse chow" (prepared according to the formula developed at BCSIR, Dhaka). All experiments on rats were carried out in absolute compliance with the ethical guide for care and use of laboratory animals. Before starting an experiment the animals were carefully marked on different parts of their body, which was later used as identification mark for a particular animal, so that the response of a particular rat prior to and after the administration could be noted separately.

\section{Treatments}

A group of equal number of rats as the drug treated group was simultaneously employed in the experiment. They were administered with distilled water as placebo as par the same volume as the drug treated group for the same number of days and this group served as the control. Prior to the experiment, they were randomly divided into 4 groups of 10 animals/sex. Thus ten rats were taken for each group for both control and the experimental group. After acclimatization, administration of the Ayurvedic medicinal preparation was done by intra-gastric syringe. Administration of the extract was between the hours of $10 \mathrm{am}$ and noon. At the due of the 45-day treatment period, the animals were fasted for 18 hours and also twenty-four hours after the last administration, the animals were anaesthetized using i.p. Ketamine (500 mg/kg i.p.).

\section{Growth analysis}

Careful monitoring of body weights of rats and mice of both sexes was performed in order to assess the effects of chronic administration of the formulation DVY $(40 \mathrm{ml} / \mathrm{kg})$ on the growth rates of the experimental animals throughout the 45 days drug administration period. All rats were kept under observation throughout the experimental period and were closely observed for signs of abnormalities if any be noted. An equal number of animals of the same species were also maintained as the Control group. Body weights were recorded at regular intervals (2-3 days) until the treatment period was complete. Complete statistical analysis of the initial and final growth rates was performed. The growth rate, expressed as percent increment in the body weight of the treatment group was compared with that of the Control group.

\section{Body weight: organ weight ratio analysis}

Sprague-Dawley rats of both sexes were administered with $40 \mathrm{ml} / \mathrm{kg}$ per-oral doses of the formulation DVY everyday for a period of 45 days. Another group of rats received equivalent amounts of distilled water. These two groups will be referred to as DVY and Control groups respectively. After the completion of the 45 day period, rats of both DVY and Control groups were sacrificed and examined macroscopically for external lesions, if any. Necropsy was performed to examine gross pathological lesions of various internal organs. Specific organs of interest were then removed from the carcasses; preserved in $13 \%$ formalin and sent for the evaluation of histological anomalies, if any. The tissues thus subjected to histopathological evaluation are: heart, kidney, lungs, liver, spleen, thymus, stomach and caecum, pancreas, adrenal glands, urinary bladder and reproductive organs, which include testis, seminal vesicles, prostate gland and epididymis in case of males and ovaries, fallopian tube and uterus in case of females. In case of organs such as the heart, lungs, liver and spleen, portions of these tissues were excised and preserved for histological examination, while the remaining portions were dried for determination of water content. Stomach and caecum contents were 
first removed; the organs were then rinsed thoroughly in normal saline and preserved. All the remaining tissues were preserved as a whole.

\section{Blood samples collection.}

Blood samples were collected from post vena cava and transferred into heparinised tubes immediately.

\section{Preparation of plasma}

Blood was then centrifuged at $4,000 \mathrm{~g}$ for 10 min using bench top centrifuge (MSE Minor, England) to remove red blood cells and recover plasma.

Plasma samples were separated and were collected using dry Pasteur pipette and stored in the refrigerator for analyses. All analyses were completed within $24 \mathrm{~h}$ of sample collection.

\section{Determination of biochemical parameters}

Biochemical analysis was carried out on serum, to assess the state of the liver and kidney. Biochemical studies involved analysis of parameters such as total protein, serum albumin, blood urea nitrogen (BUN), bilirubin (total and direct) and creatinine. Total protein content of the samples was assayed by the Biuret method (Plummer, 1978; Yakubu et al., 2006). Serum albumin concentration was determined using the method of Doumas et al (1971). Triglycerides and total cholesterol concentration as well as protein content were evaluated using assay kits (purchased from Sigma Chemical Co, St Louis, MO, USA). Serum total cholesterol and high-density lipoprotein cholesterol were determined using
Randox Laboratory kit reagents. Serum triacylglycerol level was estimated using Randox Laboratory test kit and VLDLcholesterol was calculated using the formula $\mathrm{TG} / 2.2 \mathrm{mmol} / \mathrm{l}$. Low density lipoprotein (LDL) cholesterol was determined by differential subtraction of the sum of the cholesterol fractions from the total cholesterol. The method of Evelyn and Malloy (1938) was employed to determine the serum bilirubin concentration of the samples. The procedure of Tietz et al (1994) (Atere and Ajao, 2009) was used to determine serum creatinine concentration while the serum urea concentration was determined by the method of Kaplan (1965). The absorbances of all the tests were determined using spectrophotometer (UV-Visible Spectrophotometer Model No. UV-1601 PC).

\section{Statistical Analysis}

The group data were expressed as Mean \pm SEM. Unpaired "t" tests were done for statistical significance tests. SPSS (Statistical Package for Social Science) for WINDOWS (Ver. 11) was applied for the analysis of data. Differences between groups were considered significant at $p<0.05,0.01$, and 0.001 .

\section{RESULTS AND DISCUSSION}

Effect of Darvyadi Kvatha Curnaon various parameters of liver function in male and female rats are shown in Table 2 and Table 3 respectively. Effects on male and female rats regarding kidney function parameters are presented in Table 4 and Table 5 respectively.

After the administration of DVY preparation for a period of 45 days, the following

Table 2: Effect of Darvyadi Kvatha Curnaon various parameters of liver function in male rats.

\begin{tabular}{|c|c|c|}
\hline PARAMETERS & Control Male (Mean \pm SEM) & Darvyadi Kvatha Curna (DVY) Male (Mean \pm SEM) \\
\hline Total protein & $5989.1636 \pm 114.3851$ & $6153.5696 \pm 89.9672(2.75 \%$ incr.,p=0.073) \\
\hline Albumin & $2962.2611 \pm 80.1187$ & $3472.1494 \pm 69.7476(\mathbf{1 7 . 2 1} \% \text { incr., } p=0.001)^{\star \star \star}$ \\
\hline Triglycerides & $49.8602 \pm 4.6468$ & $34.3286 \pm 0.8152(31.15 \% \text { decr., } p=0.001)^{\star \star \star}$ \\
\hline Total cholesterol & $37.4927 \pm 4.0334$ & $35.9483 \pm 1.6675(4.12 \%$ decr.,p=0.259) \\
\hline VLDL & $9.9729 \pm 0.9291$ & $11.7835 \pm 0.2328(\mathbf{1 8 . 1 6} \%$ incr.,p=0.203) \\
\hline LDL & $7.2304 \pm 1.2526$ & $6.3109 \pm 0.2726(\mathbf{1 2 . 7 2} \%$ decr.,p=0.026) \\
\hline HDL & $20.2901 \pm 1.8523$ & $20.0732 \pm 0.4621(1.07 \%$ decr., $p=0.798)$ \\
\hline Bilirubin & $0.01442 \pm 0.0061$ & $0.007012 \pm 0.0002953(51.37 \% \text { decr., } p=0.001)^{\star \star \star}$ \\
\hline
\end{tabular}


biochemical content in the plasma in both the male and female rat groups were determined.

In the study the total protein content in the plasma was increased $(2.75 \%)$ in the DVY treated male rats. The result showed no chronic administration of the traditional medicine the triglyceride level was $31.15 \%$ decreased in male rats group. Also insignificant decrease was noted in the total Cholesterol and HDL content in the plasma

Table 3: Effect of Darvyadi Kvatha Curnaon various parameters of liver function in female rats.

\begin{tabular}{lll}
\hline PARAMETERS & Control Female(Mean \pm SEM) & Darvyadi Kvatha Curna (DVY) Female (Mean \pm SEM) \\
\hline Total protein & $6541.2872 \pm 452.6064$ & $6964.1727 \pm 187.9462(6.46 \%$ incr.,p=0.199) \\
Albumin & $3450.0465 \pm 193.8229$ & $3914.5068 \pm 65.5904(\mathbf{1 3 . 4 6 \%} \text { incr.,p=0.001) })^{\star \star \star}$ \\
Triglycerides & $62.8226 \pm 8.2458$ & $56.8741 \pm 1.3647(9.47 \%$ decr.,p=0.048) \\
Total cholesterol & $50.3236 \pm 1.2016$ & $48.2508 \pm 0.8233(\mathbf{4} .12 \%$ decr.,p=0.311) \\
VLDL & $12.5647 \pm 1.6493$ & $11.6923 \pm 0.3963(6.94 \%$ decr.,p=0.195) \\
LDL & $15.2669 \pm 1.9932$ & $14.8914 \pm 0.5118(\mathbf{2 . 4 6} \%$ decr.,p=0.567) \\
HDL & $22.4932 \pm 1.3675$ & $22.3179 \pm 0.6876(\mathbf{0 . 7 8} \%$ decr.,p=0.952) \\
Bilirubin & $0.0231 \pm 0.0072$ & $0.03081 \pm 0.002462(33.38 \%$ incr.,p=0.001)
\end{tabular}

significant difference between the control and the DVY treated groups; but the $p$ value, though was not significant yet it was noticeable $(p=0.073)$. Interestingly, the albumin content was significantly increased $(17.21 \%)$ in DVY treated male rats. In the female rats group the total protein and the albumin content in the plasma were also with $4.12 \%$ and $1.07 \%$ decrease respectively. Besides insignificant increase was noted in the VLDL content in the plasma with $18.16 \%$ increase respectively. But only in the case of the content of the LDL in plasma a statistically significant decrease (12.72 \% decr.) was noted. In the female rats there was a statistically significant decrease in the Triglycerides content in the plasma. Here the

Table 4: Effect of Darvyadi Kvatha Curnaon various parameters of kidney function in male rats.

\begin{tabular}{|c|c|c|}
\hline PARAMETERS & Control Male(Mean \pm SEM) & Darvyadi Kvatha Curna (DVY) Male (Mean \pm SEM) \\
\hline Creatinine & $0.3954 \pm 0.0082$ & $0.4044 \pm 0.01252(2.28 \%$ incr., $p=0.072)$ \\
\hline Urea & $33.8681 \pm 3.2647$ & $29.8393 \pm 0.7868(11.90 \% \text { decr.,p=0.001 })^{\star \star *}$ \\
\hline Uric acid & $0.7038 \pm 0.0782$ & $0.6214 \pm 0.01395(11.71 \% \text { decr.,p=0.037) })^{\star}$ \\
\hline
\end{tabular}

increased in comparison to their control groups. A statistically significant (13.46\%) increase was noted only in the case of albumin. In the male rats there was a test medicine also decreased the triglyceride level by $9.47 \%$ in female rats group. Also a statistically insignificant decrease in the total Cholesterol, VLDL, LDL and HDL content in

Table 5: Effect of Darvyadi Kvatha Curnaon various parameters of kidney function in female rats.

\begin{tabular}{lll}
\hline PARAMETERS & Control Male(Mean \pm SEM) & Darvyadi Kvatha Curna (DVY) Male (Mean \pm SEM) \\
\hline Creatinine & $0.8863 \pm 0.0454$ & $0.5619 \pm 0.01816(36.60 \% \text { decr.,p=0.001 })^{\star \star *}$ \\
Urea & $54.7279 \pm 2.7033$ & $50.5011 \pm 1.4153(7.72 \% \text { decr.,p=0.001 })^{\star \star *}$ \\
Uric acid & $0.8693 \pm 0.0692$ & $0.9708 \pm 0.02614(11.68 \% \text { incr., } \mathrm{p}=\mathbf{0 . 0 0 1})^{\star \star *}$ \\
\hline
\end{tabular}

statistically significant decrease in the Triglycerides content in the plasma. After the plasma was noted with $4.12 \%, 6.94 \%$, $2.46 \%$ and $0.78 \%$ decrease respectively. 
In the male rats there was a statistically significant decrease $(51.37 \%)$ in the Bilirubin content in the plasma. In the female rats there was a statistically significant increase $(33.38 \%)$ in the Bilirubin content in the plasma. There was an increase in the plasma creatinine $(2.28 \%)$ in the DVY treated male rats, though this increase was not significant, yet noticeable $(p=0.072)$. On the contrary, a significant decrease in the urea (11.90\%) content in plasma was noted. In female rats, there was a statistically significant decrease in both the Creatinine (36.60\%) and Urea $(7.72 \%)$ content in the plasma. It was observed that about $11.71 \%$ decrease in plasma uric acid content of DVY treated male rats in comparison to their control male rats which are statistically significant. It was observed that the female rats showed statistically significant increase in the concentration of uric acid (11.68\%) level in comparison to their control female rats. The result of the present investigation has shown that DVY has altered the biochemical parameters investigated.

\section{CONCLUSION}

Ayurvedic medicine has been practiced in this subcontinent over past 3000 years. Still now scientific validity of the plants and other materials used in this traditional medicine system is not fully explored. The current study may contribute to the exploration and better understanding of this system. Treatment with Darvyadi Kvatha Curna (DVY) can significantly cure Shwetapradara in a cost effective manner.

\section{REFERENCES}

Bose B, Bose C (1996). Evaluation of Lukol in Leucorrhoea and Leucorrhoea Associated with Pelvic Inflammatory Disease - A Clinical Trial. The Antiseptic. (93), 2, 49. Available at:

http://www.himalayahealthcare.com/pdf_files/lukol007.pdf . [Accessed on: October 11, 2012]

Kulkarni RN, Durge PM (2005). A study of leucorrhoea in reproductive age group women of Nagpur City. Indian $\mathrm{J}$ Public Health. 49(4): 238-9. PMid:16479906

Morphemeremedies, Online document. Leucorrhoea treatment. Available at:

http://morphemeremedies.com/leucorrhoea.htm. [Accessed on: November 9, 2011]

Ghani A (2005). Textbook of Pharmacognosy, Part-1. Published by Malek A, Mirpur- 12, Dhaka. pp. 239-250.

Anonymous (1992). Bangladesh National Formulary of Ayurvedic Medicine 1992 (Approved by the Government of Bangladesh vide Ministry of Health and Family Welfare Memo No. Health-1/Unani-2/89/(Part-1) 116 dated 3-61991). National Unani and Ayurvedic Formulary Committee Bangladesh Board of Unani and Ayurvedic Systems of Medicine.

Doumas BT, Watson WA, Biggs HG (1971). Albumin standards and the measurement of serum albumin with bromcresol green. Clin Chim Acta. 31(1):87-96. http://dx.doi.org/10.1016/0009-8981(71)90365-2

Yakubu MT, Adesokan AA, Akanji MA (2006). Biochemical changes in the liver, kidney and serum of rat following chronic administration of cimetidine. African Journal of Biomedical Research. 9: 213-218.

Kaplan MM (1965). Urea nitrogen and urinary ammonia. In: Meites S (Eds.). Standard Method of Clinical Chemistry. Academic Press Inc., New York. pp 245-256.

Evelyn KA, Malloy HT (1938). Micro Determination of oxyhaemoglobin, methaemoglobin and sulphaemoglobin in a single sample of blood. J Boil Chem. 126: 655-661.

Tietz NW, Prude EL, Sirgard- Anderson O (1994). Tietz textbook of Clinical Chemistry. Burtis CA Ashwood ER (eds.). W.B. Sauders Company, London. pp. 1354-1374.

Atere TG, Ajao AT (2009). Toxicological implications of crude alkaloidal fraction from Cnestis ferruginea D.C root on liver function indices of male Wistar rats. International Journal of Biomedical and Health Sciences. 9(3): 145-156.

Plummer DT (1978). An introduction to practical Biochemistry (2nd Ed.). McGraw-Hill, London. pp. 144-145.

Khan MR (1994). Sicknesses, Diseases, Treatments and Medical Costs by Socioeconomic Variables in

Bangladesh (Research Monograph No. 15). Bangladesh Institute of Development Studies, Dhaka.

WHO (2002). WHO Traditional Medicine Strategy 20022005. World Health Organization, Geneva. Available at: http://whqlibdoc.who.int/hq/2002/who_edm_trm_2002.1.pdf. [Accessed on: August 21, 2011] 